\title{
Knowledge and Nutritional Habits of Older Adults Regarding Immunity at Qena City
}

\author{
Nadia Omar Emam ${ }^{1}$, Hoda Diab Fahmy ${ }^{2}$, Mohamed Kamal Alsayed ${ }^{3}$, Asmaa Kamal Hassan ${ }^{4}$, HuiJun Chih ${ }^{5}$ \\ ${ }^{1}$ Assistant Lecturer of Gerontological Nursing, South Valley University, Egypt. \\ ${ }^{2}$ Professor of Community Health Nursing, Faculty of Nursing, Assuit University, Egypt. \\ ${ }^{3}$ Professor of Food Science \& Technology, Faculty of Agriculture, Assiut University, Egypt. \\ ${ }^{4}$ Assist. Professor of Community Health Nursing, Faculty of Nursing, Assiut University, Egypt. \\ ${ }^{5}$ Lecturer of Epidemiology and Biostatistics, School of Public Health, Curtin University, Australia.
}

\begin{abstract}
Background: It is well-accepted that nutritional status plays a significant role in immune response especially among older adults. So, it is necessary to pay attention to their knowledge and nutritional habits. Aim: To assess knowledge and nutritional habits of older adults regarding immunity at Qena city. Design: A correlational descriptive design. Method: Total coverage of all older adult members of the elderly club at Qena city by using Mini-Mental State Examination (MMSE) scale. A convenient sample of 103 older adults who fulfilled the inclusion criteria was selected. The data was collected by using structured interview questionnaire which consists of three parts; part one: Socio-demographic characteristics. Part two: Knowledge of older adults regarding immunity and nutritional elements that enhance it. Part three: Dietary intake (24 hours recall method). Results: The vast majority (94.2\%) of the study subjects have poor knowledge level. Harmful dietary habits among the study subjects as high carbohydrates sources consumption and low fruits and vegetables consumption, using butter for food preparation, and frying most of food are highly prevalent among elderly. Conclusion: The vast majority of the study subjects have poor knowledge level as well as unhealthy nutritional habits. Recommendation: Health education about immunity and dietary intakes of older adults are necessary to improve their knowledge and correct the dietary habits.
\end{abstract}

\section{Keywords: Knowledge, Nutritional Habits, Immunity, Older Adults \& Nutrition.}

\section{Introduction}

The older adult population is one of the fastest growing segments of the population worldwide. According to the WHO, the proportion of old individuals (over the age of 60 years) will rise to $22 \%$ of the world population by 2050 (WHO, 2015a) and the life expectancy in Egypt also increased to be 69 years for male and 73 years for female (WHO, 2015b).

It was thoughtful that the demographic changes increase the diseases burden and elevate the older adults' issues attention. Appropriate diet is the most important concern for older adults because of two main causes. First; the age related changes of gastrointestinal system and nutritional related changes. Second; nutrition has a major role in prevention and treatment of many serious diseases (Kourkouta et al., 2016).

Many studies confirmed that malnutrition is a common problem among elderly in the developing countries especially at rural areas due to poverty, and lack of nutritional awareness (Ali et al., 2013). In these countries as Egypt, Bangladesh, and Oman, older adult food intake is less than daily requirement and unsatisfactory (Ibrahim et al., 2013, Al Riyami et al., 2010; El-damhougy et al., 2010).

Nutrition and immunity have been linked to each other for centuries. In the last decade, systematic studies have confirmed that nutrient deficiencies can alter the immune response and lead to a higher incidence of infections resulting in increased mortality. Other impairments of immune function have been reported for moderate deficiencies of trace minerals and vitamins. The interactions between nutrition and the immune system have clinical, practical, and public health importance ( Zapatera et al., 2015, Oketcha, 2011).

Appropriate balanced diet positively affects all body systems in contrast to malnutrition (over or undernutrition) that negatively affect all the body systems as well as mental and psychological conditions. There are many examples of the conditions which be affected by the diet as cardiovascular diseases as hypertension, respiratory disorders as lung infections, endocrine illness as diabetes, immunity impairment as infection, mental disturbances as cognitive impairment, and psychological disorders as depression (Kourkouta et al., 2016; Morris et al., 2016, Lee et al., 2009).

\section{Significance of the study}

Based on the existed researches, nutritional habits are a major factor that determines the older adults' food intake. In developed and developing countries, nutritional habits as energy and protein intake, fruits and vegetable consumption, associated with older 
adults health status (Rakıcıoğlu et al., 2016, Laurenti et al., 2015, Gómez-Busto et al., 2014, Lasheras et al., 2003).

Older adults present a unique set of nutrition challenges, as they may be deficient in some essential nutrients including protein, vitamins, and minerals, although they are not aware of these deficiencies. Knowledge and nutritional habits assessment is critical to support health, reduce the risk and delay the onset of chronic diseases in this population (Wunderlich et al., 2009, Krondl et al., 2008).

\section{The Aim of the study}

Assess the knowledge and nutritional habits of older adults regarding the immunity.

\section{Research questions}

- What is the level of the study subjects' knowledge regarding immunity?

- What are the common nutritional habits that affect on the immunity of the study subjects?

\section{Subjects \& Method \\ Subjects}

Research design: a correlational descriptive design.

\section{Setting:}

The study was conducted at the elderly club, the only elderly club at Qena city, Egypt which provides many services for older adults from any socio-economic class such as recreational activities and health services (medical \& physiotherapy).

\section{Subjects}

\section{Subjects selection technique}

Total coverage of all older adult members of the elderly club at Qena city by using Mini-Mental State Examination (MMSE) scale and ask for willing to participate. A convenient sample of 103 older adults (both sex) from total 150 members who fulfilled the inclusions criteria was selected.

\section{Inclusion criteria}

1. Aged 60 years and older.

2. Free from any mental diseases according to their score of MMSE scale (he/she must obtain 24-30 score).

\section{Method}

Tool of the study: one tool (Structured interview questionnaire) was used to collect the data.

This tool was developed by the researcher based on relevant literature. Also, tool validity was tested for content by five nursing and medical experts in the related fields. The reliability was measured by Cronbach's Alpha and it was reliable 0.90. It consists of three parts.

Part (1): Socio-demographic characteristics as age, sex, and level of education.
Part (2): Knowledge of older adults regarding immunity and nutritional elements that enhance it. This part (knowledge level) contains eleven open questions which finally categorized as (incorrect answer $=0$ degree, incomplete and correct answer $=$ 1 degree and complete and correct answer $=2$ degree) and forty-four multiple choice questions (scores according to the number of the correct answers). Total questions number is 55 with maximum 90 scores. Knowledge level variable is not normally distributed and the researcher treated it as a categorical variable into three categories:

- Poor knowledge $(<50 \%)$

- Fair knowledge (50: <70 \%)

- Good knowledge (70 and above \%).

Part (3): Dietary intake to assess nutritional habits such as frequency of food consumption and preparation methods by using 24 hours recall method. The researcher asked the participants to report all food taken at the last 24 hours in addition to preparation methods, substances used for preparation, and the time.

\section{Study phases}

Administrative phase: The study was approved by the college of Nursing, Assiut University, Egypt. At the same time, permission to carry out the study from the director of the elderly club after explanation the purpose of the study was obtained. A verbal consent from elders to participate in the study was obtained after explanation of the study purpose.

A pilot study was done on $10 \%$ of older adults who fulfilled the inclusion criteria to assess the tools for their applicability, clarity, and necessary modifications were done accordingly.

Data Collection: The researcher used the MMSE as first step to assess the cognitive status of each members of elderly club to exclude member who get less than twenty-four (24) score. This scale was developed by Folstein et al, 1975 and consists of 11 simple questions or tasks grouped into five (5) cognitive domains (Folstein et al., 1975) which are orientation, registration of three words, attention \&calculation, recall of three words and language. A possible score of thirty (30) is used to provide a picture of an individual's present cognitive performance based on direct observation of completion of test items/tasks. A score which less than twenty-four (24) is the generally an accepted cutoff indicating the presence of cognitive impairment. Levels of impairment have been classified as the following:

- No impairment: score $=24-30$

- Mild impairment: score = 18-24

- Severe impairment: score $=0-17$ 
The validity and reliability of this scale were assessed previously. The data were collected by using the previously mentioned tool from first to mid of May.

Ethical consideration

- Verbal consent was obtained from every elderly person included in the study.

- Each elderly person was assured about the Confidentiality of the collected data.

- The privacy of each elderly patient was maintained.

\section{Results}

Table (1): Distribution of the study subjects according to socio-demographic characteristics.

\begin{tabular}{|c|c|c|}
\hline Socio-demographic characteristics. & $\mathrm{N}=\mathbf{1 0 3}$ & $\%$ \\
\hline \multicolumn{3}{|l|}{ Age categories } \\
\hline$-\quad<65$ years & 50 & 48.5 \\
\hline - $\quad 65-70$ years & 26 & 25.2 \\
\hline$-\quad>70$ years & 27 & 26.2 \\
\hline \multicolumn{3}{|l|}{ Sex } \\
\hline - Female & 51 & 49.5 \\
\hline - $\quad$ Male & 52 & 50.5 \\
\hline \multicolumn{3}{|l|}{ Marital status } \\
\hline - $\quad$ Married & 77 & 74.8 \\
\hline - $\quad$ Widowed & 26 & 25.28 \\
\hline \multicolumn{3}{|l|}{ Education level } \\
\hline - $\quad$ Illiterate & 34 & 33.0 \\
\hline - $\quad$ Primary / Read and write & 29 & 28.2 \\
\hline $\begin{array}{ll}- & \text { Secondary education }\end{array}$ & 26 & 25.2 \\
\hline - $\quad$ High education & 14 & 13.6 \\
\hline \multicolumn{3}{|l|}{ Income (as their order) } \\
\hline - $\quad$ Adequate & 68 & 66.0 \\
\hline - $\quad$ Inadequate & 35 & 34.0 \\
\hline \multicolumn{3}{|l|}{ Residence } \\
\hline - $\quad$ Rural & 51 & 49.5 \\
\hline - Urban & 52 & 50.5 \\
\hline
\end{tabular}

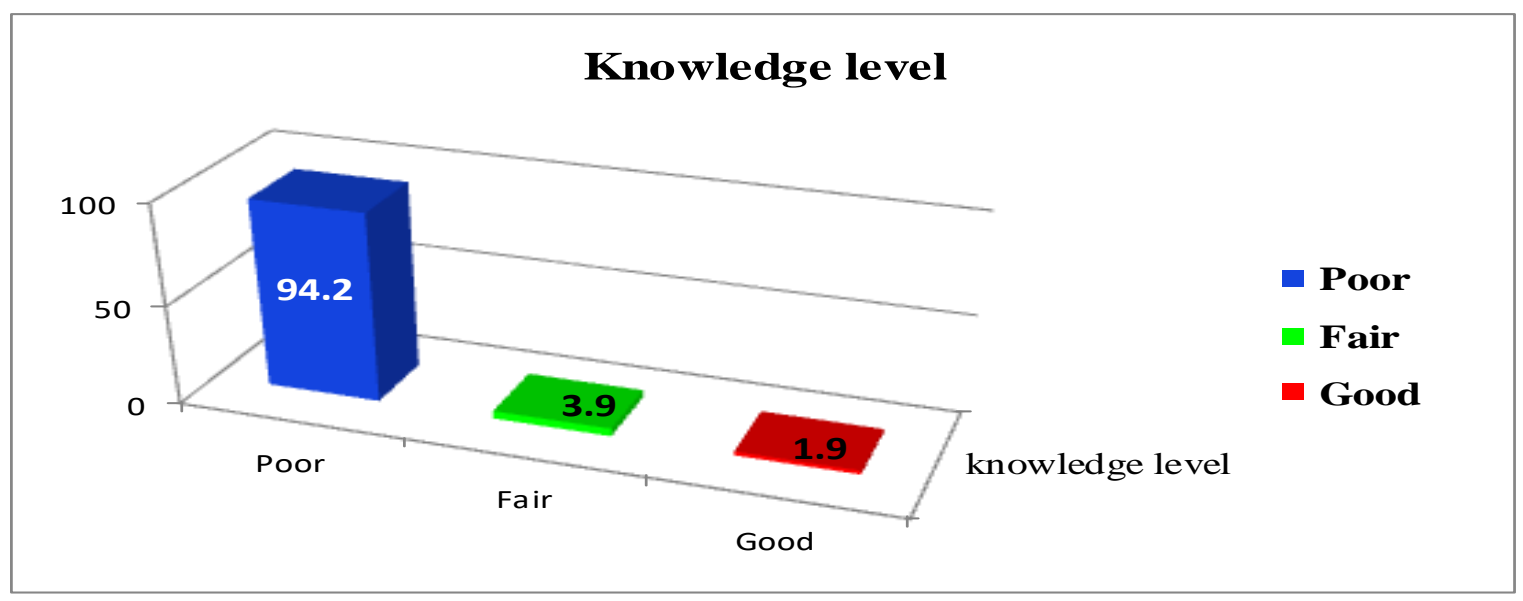

Figure (1): The distribution of the study subjects according to their knowledge level about nutrition that enhances the immunity

\section{Statistical analysis}

Data were collected on paper documents, uploaded to Microsoft Excel for storage, and transferred to STATA, version 12, for analysis. Nominal variables, such as gender, marital status, educational level and knowledge level were described using frequency counts and are presented as $N(\%)$. Chi-square $\left(x^{2}\right)$, and Cramer's V test were used to test associations between nominal variables and considered significant at $\mathrm{p} \leq 0.05$. 
Table (2) Distribution of the study subjects by Socio-demographic characteristics according to their knowledge level about nutrition that enhances the immunity.

\begin{tabular}{|c|c|c|c|c|c|}
\hline \multirow{2}{*}{ Socio-demographic characteristics } & \multicolumn{3}{|c|}{ Knowledge level } & \multirow{2}{*}{ Total } & \multirow{2}{*}{ P-Value* } \\
\hline & Poor & Fair & Good & & \\
\hline \multicolumn{6}{|l|}{ Age categories } \\
\hline$-\quad<65$ years & 47 & 1 & 2 & 50 & \multirow{3}{*}{0.484} \\
\hline - $\quad 65-70$ years & 25 & 1 & 0 & 26 & \\
\hline - $\quad>70$ years & 25 & 2 & 0 & 27 & \\
\hline \multicolumn{6}{|l|}{ Sex } \\
\hline - Male & 49 & 2 & 0 & 51 & \multirow{2}{*}{0.368} \\
\hline - Female & 48 & 2 & 2 & 52 & \\
\hline \multicolumn{6}{|l|}{ Educational level } \\
\hline - $\quad$ Illiterate & 33 & 1 & 0 & 34 & \multirow{4}{*}{0.339} \\
\hline - $\quad$ Primary / Read and write & 28 & 0 & 1 & 29 & \\
\hline - $\quad$ Secondary education & 25 & 1 & 0 & 26 & \\
\hline - $\quad$ High education & 11 & 2 & 1 & 14 & \\
\hline
\end{tabular}

* Significant at $\leq 0.05$ as reported from Cramer's V test.

Table (3): Distribution of the study subjects according to frequency consumption of usual food.

\begin{tabular}{|c|c|c|c|c|c|c|}
\hline \multirow{3}{*}{ Usual food } & \multicolumn{6}{|c|}{$\begin{array}{l}\text { Frequency of usual food per week } \\
\qquad N=103\end{array}$} \\
\hline & \multicolumn{2}{|c|}{ Not consumed } & \multicolumn{2}{|c|}{ Not everyday } & \multicolumn{2}{|c|}{ Everyday } \\
\hline & N. & $\%$ & N. & $\%$ & N. & $\%$ \\
\hline Meat & 9 & 8.7 & 94 & 91.3 & 0 & 0.0 \\
\hline Poultry & 0 & 0.0 & 103 & 100.0 & 0 & 0.0 \\
\hline Fishes & 4 & 3.9 & 99 & 96.1 & 0 & 0.0 \\
\hline Eggs & 24 & 23.3 & 69 & 67.0 & 10 & 9.7 \\
\hline Legumes \& beans & 1 & 1.0 & 19 & 18.4 & 83 & 80.6 \\
\hline Milk and milk products & 5 & 4.8 & 30 & 29.1 & 68 & 66.0 \\
\hline Vegetables & 0 & 0.0 & 46 & 44.7 & 57 & 55.3 \\
\hline Fruits & 0 & 0.0 & 59 & 57.3 & 44 & 42.7 \\
\hline Bread & 0 & 0.0 & 0 & 0.0 & 103 & 100.0 \\
\hline Rice, pasta, taro and potato & 0 & 0.0 & 51 & 49.5 & 52 & 50.5 \\
\hline Jam, Honey and molasses & 87 & 84.5 & 14 & 13.6 & 2 & 1.9 \\
\hline
\end{tabular}


Table (4) Distribution of the study subjects according to frequency consumption of usual food by income.

\begin{tabular}{|c|c|c|c|c|c|c|c|c|}
\hline \multirow{3}{*}{$\begin{array}{l}\text { Food } \\
\text { Income }\end{array}$} & \multicolumn{6}{|c|}{ Frequency of usual food per week } & \multirow{3}{*}{ Test of sig. } & \multirow{3}{*}{$\begin{array}{c}\text { P- } \\
\text { Value* }^{*}\end{array}$} \\
\hline & \multicolumn{2}{|c|}{ Not consumed } & \multicolumn{2}{|c|}{\begin{tabular}{|c|c|} 
Not \\
everyday
\end{tabular}} & \multicolumn{2}{|c|}{ Everyday } & & \\
\hline & N. & $\%$ & N. & $\%$ & N. & $\%$ & & \\
\hline \multicolumn{9}{|l|}{ Meat } \\
\hline Adequate income & 3 & 4.4 & 65 & 95.6 & 0 & 0.0 & \multirow[b]{2}{*}{ Cramer's V } & \multirow[t]{2}{*}{$0.030 *$} \\
\hline $\begin{array}{l}\text { Inadequate } \\
\text { income }\end{array}$ & 6 & 17.1 & 29 & 82.9 & 0 & 0.0 & & \\
\hline \multicolumn{9}{|l|}{ Poultry } \\
\hline Adequate & 0 & 0.0 & 68 & 100.0 & 0 & 0.0 & \multirow[t]{2}{*}{ Cramer's V } & \multirow[t]{2}{*}{ 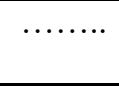 } \\
\hline Inadequate & 0 & 0.0 & 35 & 100.0 & 0 & 0.0 & & \\
\hline \multicolumn{9}{|l|}{ Fish } \\
\hline Adequate & 1 & 1.5 & 67 & 98.5 & 0 & 0.0 & \multirow{2}{*}{ Cramer's V } & \multirow{2}{*}{0.077} \\
\hline Inadequate & 3 & 8.6 & 32 & 91.4 & 0 & 0.0 & & \\
\hline \multicolumn{9}{|c|}{ Legumes and beans } \\
\hline Adequate & 1 & 1.5 & 19 & 27.9 & 48 & 70.6 & \multirow{2}{*}{ Cramer's V } & \multirow{2}{*}{$0.002 *$} \\
\hline Inadequate & 0 & 0.0 & 0 & 0.0 & 35 & 100.0 & & \\
\hline \multicolumn{9}{|l|}{ Eggs } \\
\hline Adequate & 18 & 26.5 & 40 & 58.8 & 10 & 14.7 & \multirow{2}{*}{ Cramer's V } & \multirow{2}{*}{$0.01 *$} \\
\hline Inadequate & 6 & 17.1 & 29 & 82.9 & 0 & 0.0 & & \\
\hline \multicolumn{9}{|c|}{ Milk and milk products } \\
\hline Adequate & 3 & 4.4 & 12 & 17.6 & 53 & 77.9 & \multirow{2}{*}{ Chi-squared } & \multirow{2}{*}{$0.001 *$} \\
\hline Inadequate & 2 & 5.7 & 18 & 51.4 & 15 & 42.9 & & \\
\hline \multicolumn{9}{|l|}{ Vegetables } \\
\hline Adequate & 0 & 0.0 & 20 & 29.4 & 48 & 70.6 & \multirow{2}{*}{ Cramer's V } & \\
\hline Inadequate & 0 & 0.0 & 26 & 74.3 & 9 & 25.7 & & $0.001^{*}$ \\
\hline Fruits & & & & & & & & \\
\hline Adequate & 0 & 0.0 & 30 & 44.1 & 38 & 55.9 & Cramer's V & \\
\hline Inadequate & 0 & 0.0 & 29 & 82.8 & 6 & 17.1 & & $0.001^{*}$ \\
\hline Bread & & & & & & & & \\
\hline Adequate & 0 & 0.0 & 0 & 0.0 & 51 & 100.0 & Cramer's V & \\
\hline Inadequate & 0 & 0.0 & 0 & 0.0 & 52 & 100.0 & & \\
\hline Rice, pasta, taro a & id po & & & & & & & \\
\hline Adequate & 38 & 55.9 & 5 & 7.3 & 25 & 36.8 & Chi-squared & \\
\hline Inadequate & 12 & 34.3 & 20 & 57.1 & 3 & 8.6 & -int-squarta & $0.001^{*}$ \\
\hline Jam, Honey and $n$ & olass & & & & & & & \\
\hline Adequate & 58 & 85.3 & 8 & 11.7 & 2 & 3.0 & & 0464 \\
\hline Inadequate & 29 & 82.9 & 6 & 17.1 & 0 & 0.0 & Cramer's V & 0.404 \\
\hline
\end{tabular}

* Significant at $\leq 0.05$ 
Table (5): Distribution of the study subjects according to preparation method of usual food.

\begin{tabular}{|l|c|c|c|c|}
\hline \multirow{2}{*}{ Usual food } & \multicolumn{3}{c|}{ Preparation methods } \\
\cline { 2 - 5 } & \multicolumn{2}{c|}{ Boiled or grilled } & \multicolumn{2}{c|}{ Fried } \\
\cline { 2 - 5 } & $\mathbf{N}$ & $\%$ & N. & \% \\
\hline Red meat & 18 & 25.7 & 52 & 74.3 \\
\hline Fatty meat & 9 & 20.5 & 35 & 79.5 \\
\hline Canned meat & 1 & 8.3 & 11 & 91.7 \\
\hline Non-fatty poultry (Chicken, rabbit) & 25 & 24.3 & 78 & 75.7 \\
\hline Fatty poultry (Duck, pigeon) & 13 & 22.4 & 45 & 77.6 \\
\hline Fresh fishes & 1 & 1.0 & 101 & 99.0 \\
\hline Frozen fishes & 0 & 0.0 & 12 & 100.0 \\
\hline Eggs & 41 & 51.9 & 38 & 48.1 \\
\hline Legumes \& beans & 102 & 100.0 & 0 & 0.0 \\
\hline Cooked Vegetable & 2 & 1.9 & 101 & 98.0 \\
\hline Rice / pasta & 1 & 1.0 & 101 & 99.0 \\
\hline Potato, sweet potato, taro & 24 & 27.0 & 65 & 73.0 \\
\hline
\end{tabular}

Table (6): Distribution of the study subjects according to substance used for usual food preparation.

\begin{tabular}{|l|c|c|c|c|c|c|}
\hline \multirow{2}{*}{ Usual food } & \multicolumn{9}{c|}{ Substance used\# } \\
\cline { 2 - 7 } & \multicolumn{2}{|c|}{ Vegetable Oil } & \multicolumn{2}{c|}{ Margarine } & \multicolumn{2}{c|}{ Butter (milk) } \\
\cline { 2 - 7 } & $\mathbf{N}$ & $\mathbf{\%}$ & $\mathbf{N}$ & $\mathbf{\%}$ & $\mathbf{N .}$ & $\mathbf{\%}$ \\
\hline \hline Red meat & 12 & 17.1 & 22 & 31.4 & 36 & 51.4 \\
\hline Fatty meat & 6 & 13.6 & 6 & 13.6 & 32 & 72.7 \\
\hline Canned meat & 5 & 41.7 & 0 & 0.0 & 7 & 58.3 \\
\hline Non-fatty poultry (Chicken, rabbit) & 16 & 15.7 & 24 & 23.5 & 62 & 60.8 \\
\hline Fatty poultry (Duck, pigeon) & 6 & 10.3 & 17 & 29.3 & 35 & 60.3 \\
\hline Fresh fishes & 102 & 100 & 0 & 0.0 & 0 & 0.0 \\
\hline Frozen fishes & 12 & 100 & 0 & 0.0 & 0 & 0.0 \\
\hline Eggs & 1 & 2.5 & 6 & 15.0 & 33 & 82.5 \\
\hline Legumes \&beans & 44 & 43.1 & 12 & 11.8 & 46 & 45.1 \\
\hline Cooked Vegetable & 18 & 17.5 & 20 & 19.4 & 65 & 63.1 \\
\hline Rice / pasta & 19 & 18.6 & 22 & 21.6 & 61 & 59.8 \\
\hline Potato, sweet potato, taro & 61 & 78.2 & 5 & 6.4 & 12 & 15.4 \\
\hline
\end{tabular}

\# more than one answer

Table (1): Shows the distribution of the study subjects according to socio-demographic characteristics. Pertaining to age categories (from 60 to 64, and from 65 and above), sex (female and male), and residence (rural and urban), the study subjects nearly split in half $(48.5,51.5,49.5,50.5$, 49.5 , and $50.5 \%$ respectively). Concerning marital status, income, and level of education, most of the study subjects are married, approximately two thirds have adequate income, and approximately one third are illiterate (74.8, 66, and $33 \%$ respectively).

Figure (1): Shows the distribution of the study subjects according to their knowledge level about nutrition that enhances the immunity. It is observed that the vast majority $(94.2 \%)$ of the study subjects have poor knowledge level.
Table (2): Shows the distribution of the study subjects by Socio-demographic characteristics according to their knowledge level about nutrition that enhances the immunity. It is noticed that, there are no statistical significant difference of the knowledge level between all age categories, male and female, and educational levels $(0.484,0.368,0.339$ consecutively).

Table (3): Reflects the distribution of the study subjects according to frequency consumption of usual food. It is noticed that all (100.0\%) subjects didn't consume poultry daily and no one consumed meat, and fishes every day. Also, most of them (80.6\%) consumed Legumes daily. Regarding vegetables, and rice, pasta, taro and potato, more than half consumed them daily $(55.3 \%, 50.5 \%$ respectively). Concerning 
fruits, $57.3 \%$ of the subjects didn't consume fruits daily.

Table (4): Shows the distribution of the study subjects according to frequency consumption of usual food by income. It is clearly noticed that, there are a highly statistical significance differences between the consumption frequency of subjects who have adequate income and who have inadequate income regarding most of usual food as meat, legumes and beans, eggs, milk and milk products, vegetables, fruits, and rice, pasta, taro and potato $(\mathrm{P}>0.05)$.

Table (5): Explicates the distribution of the study subjects according to preparation method of usual food. It is interesting to observe that most of the study subjects consume red meat, fatty meat, canned meat, non-fatty poultry (Chicken, rabbit), fatty poultry (Duck, pigeon), fresh fishes, frozen fishes, cooked vegetable, rice /pasta, and potato, sweet potato, taro as fried $(74.3,79.5,91.7,75.7,77.6,99$, $100,98.0,99$, and 73 respectively).

Table (6): Shows the distribution of the study subjects according to substance used for usual food preparation. It is observed that more than one half of the study subjects who consumed red meat, canned meat, non-fatty poultry (Chicken, rabbit), fatty poultry (duck, pigeon), cooked vegetable, and rice /pasta used milk butter for preparation $(51.4,58.3$, $60.8,60.3,63.1$, and $59.8 \%$ respectively).

\section{Discussion}

Adequate nutrition has a fundamental role in both elderly health promotion and disease management. The older adult required diet is different from the young and influenced by several age related changes and other factors which increase the risk of nutritional problems in elderly as vitamins and minerals deficiency (Doan et al., 2013, Watson \& Ebrary, 2009, Morley et al., 2007).

This study aimed to assess the older adults' knowledge and nutritional habits regarding the immunity. The study subjects nearly split in half regarding age groups, sex, and residence. This is the strength point to compare between them.

The current study revealed that the vast majority of the subjects had poor knowledge level about nutrition that enhances the immunity. This result may be related to lack of interest and awareness among educated and non-educated elderly. Similar results were obtained from a study about malnutrition problems at El Haram dialysis Centre, Giza, Egypt which reflected that "Don't know" responses of the elderly patients were $82.9 \%$ (Hegazy et al., 2013) At the same line, at Menoufia University Hospital, Egypt, El-sol et al confirmed that all of the studied elderly subjects had inadequate knowledge in the pre educational intervention about osteoporosis (El-sol et al., 2016).

According to the current study, the vast majority of the male or female subjects at all age categories, and at all educational level had poor knowledge level. This findings is in agreements with the previous study results conducted in Transylvania University in Brasov, Romania, by Topală who reported that, the ability to learn anything and anywhere does not significantly vary between age categories (Topală, 2014).

Contrary to the present result, Yang, et al, investigated the interactive effects of gender and age on learning satisfaction among older adult students who attend senior university program in China and they demonstrated that respondents' learning satisfaction scores were higher for males than for females for the age range of 55-60. For the group aged 71 year and above, females scored higher than males (Yang et al., 2016).

The current study reflects poor nutritional habits in terms of frequency of consumption, preparation methods, and substances used. The usual food types consumed in Egypt are beef, poultry, fishes, beans and legumes, available vegetables and fruits are obtained in Egypt each in its own growing season, some in winter, other in summer such as orange, watermelon, grape, pear, mango, capsicum, green beans, peas, tomato, spinach) bread (white, whole), rice, pasta, potatoes, jam, molasses, and beverages such as tea, fruits juice.

The current study reported that consumption of the carbohydrate sources were more frequent (daily) than the protein sources or vegetables and fruits. However, it is recommended for older adults to decrease consumption of carbohydrates and increase fruits and vegetables intake. This can be explained by two reasons; First, low price of carbohydrates sources such as potato, rice, and pasta compared to protein sources such as beef, poultry, and fishes as well as vegetables and fruits. This is evidenced by a highly statistical significance differences between the consumption frequency of subjects who have adequate income and who have inadequate income. The current finding is similar to the result of the study done in Italy and concluded that economic conditions affect the status of intake of some foods in elderly, including fish, meat and dairy products (Giuli et al., 2012) Second, poor knowledge score may lead to the harmful dietary habits among older adults.

This findings is in agreements with the study was done in Egypt by El-damhougy et al, which concluded that the micro-nutrient intake which mainly obtained from vegetables and fruits was found 
to be lower than the recommended dietary allowance (RDA) among institutionalized elderly

(El-damhougy et al., 2010). Also, the current results is in the same line with the study done in Alexandria, Egypt as well by Ibrahim et al, which concluded that the dietary pattern of the elders is far from being satisfactory (Ibrahim et al., 2013) Similar results were obtained in previous study in the Nizwa wilayat, Al Dakhliya region of Oman by Al Riyami et al, who confirmed that $88.6 \%$ of the subjects had inadequate vegetable intake and there are poor nutritional habits among participants (Al Riyami et al., 2010) The same results obtained from the study conducted in the Netherlands by Kamphuis et al, reported that price, and travel time to grocery shops influenced older adults' food choices (Kamphuis et al., 2015).

The common preparation methods of usual food types in Egypt are boiling, grilling, or frying using margarine (a hydrogenated oil), butter (from milk), and vegetables oil. The present study reported that frying is the most common preparation methods using butter to cook beef, poultry, and vegetable. This findings are not in agreement with the findings in Iran confirmed by Bahrami et al. who mentioned that only $18.9 \%$ of elderly still use hydrogenated vegetable oils and $24 \%$ of older people reported using frying and grilling as their primary cooking method (Bahrami et al., 2016).

\section{Conclusion}

Based on the results of the current study, it was concluded that the vast majority of the study subjects had poor knowledge level. the harmful dietary habits among the study subjects such as high carbohydrates sources consumption and low fruits and vegetables consumption, using butter for food preparation, and frying most of food are highly prevalent among elderly.

\section{Recommendation}

\section{It was recommended that}

- Health education targeting knowledge about immunity and dietary intakes of older adults are necessary to improve their knowledge and correct their dietary habits.

- Booklets and videos about healthy dietary habits should be available at all elderly clubs' library.

\section{References}

1. Al Riyami, A., Al Hadabi, S., Abd El Aty, M., Al Kharusi, H., Morsi, M., \& Jaju, S., (2010): Nutrition knowledge, beliefs and dietary habits among elderly people in Nizwa, Oman: implications for policy. Eastern Mediterranean Health Journal, 16(8), 859-867.
2. Ali, M., Karim, M., Lahiry, S., Faruquee, M., \& Yasmin, N., (2013): Gender Differentials In Nutritional Status of Elderly People In Selected Rural Areas of Bangladesh. Bangladesh Journal of Medical Science, 12(2), 150-157. doi: 10.3329/bjms.v12i2.14943

3. Bahrami, D., Mirzaei, M., \& SalehiAbargouei, A., (2016): Dietary Behaviors of Elderly People Residing in Central Iran: A Preliminary Report of Yazd Health Study. [Research]. Elderly Health Journal, 2(1), 6-13.

4. Doan, T., Melvold, R., Viselli, S., \& Waltenbaugh, C., (2013): Immunology (2nd ed.. ed.). Philadelphia: Philadelphia : Wolters Kluwer Health/Lippincott Williams \& Wilkins.

5. El-damhougy, S., Hussein, M., \& Abd Elazeem, A., (2010): Dietary Intake and Biochemical Indicators of Nutritional Status in an Institutionalized Egyptian Elderly Population. Med. J. Cairo Univ, 78(1), 385-391.

6. El-sol, A., Abd Elhy, A., \& Abd Elsalam, E., (2016): Effect of Educational Nursing Intervention About Osteoporosis on Adult's Knowledge. American Journal of Nursing Science, 5(6), 272-279. doi: 0.11648/j.ajns.20160506.16

7. Folstein M., \& Folstein S., (1975): "MiniMental State" a Practical Method for Grading the Cognitive State of Patients for the Clinician. Journal of Psychiatric Research, 12(3), 189-198.

8. Giuli, C., Papa, R., Mocchegiani, E., \& Marcellini, F., (2012): Dietary habits and ageing in a sample of Italian older people. The Journal of Nutrition, Health \& Aging, 16(10), 875-879.

9. Gómez-Busto, F., Andía-Muñoz, V., Ruiz-deAlegría, L., Rica, P., \& Mogollón, E., (2014): Nutritional status, dietary habits and social and health profile of home meal service users for elderly of Vitoria-Gasteiz. Revista Española de Nutrición Humana y Dietética, 18(3), 127-136. doi: 10.14306/renhyd.18.3.30

10. Hegazy, I., El Raghy, H., Abdel-Aziz, S., \& Elhabashi, E., (2013): Study of the effect of dietary counselling on the improvement of endstage renal disease patients. Eastern Mediterranean Health Journal, 19(1), 45-51.

11. Ibrahim, H., El Kady, H., \& Elsayed, D., (2013): Factors Affecting Nutritional Status among Elders Attending Geriatric Clubs in Alexandria, Egypt. Journal of American Science, 9(10), 183-192.

12. Kamphuis, C., de Bekker-Grob, E., \& van Lenthe, F., (2015): Factors affecting food choices of older adults from high and low socioeconomic groups: a discrete choice 
experiment. Factors affecting food choices of older adults from high and low socioeconomic groups: a discrete choice experiment, 101(4), 768-774. doi: 10.3945/ajcn.114.096776

13. Kourkouta, L., Ouzounakis, P., Monios, A., \& Iliadis, C., (2016): Nutritional habits in the elderly. Progress in Health Sciences, 6(2), 155159. doi: 10.5604/01.3001.0009.5163

14. Krondl, M., Coleman, P., \& Lau, D., (2008): Helping Older Adults Meet Nutritional Challenges. Journal of Nutrition For the Elderly, 27(3-4), 205-220. doi: $10.1080 / 01639360802261755$

15. Lasheras, C., Gonzalez, S., Huerta, J., Lombardia, C., Ibañez, R., Patterson, A., \& Fernandez, S., (2003): Food habits are associated with lipid peroxidation in an elderly population. Journal of the American Dietetic Association, 103(11), 1480-1487. doi: 10.1016/j.jada.2003.08.023

16. Laurenti, P., de Waure, C., De Meo, C., Raponi, M., Corsaro, A., Del Prete, J., Spagnolo, A., Sacchini, D., Bernabei, R., Manes Gravina, E., Landi, F., Sgadari, A., Grassi, C., \& Ricciardi, W., (2015): Food safety and nutritional habits in elderly: knowledge to promoting active ageing. The European Journal of Public Health, 25(supp13). doi: 10.1093/eurpub/ckv175.260

17. Lee, K., Cheong, H., Kim, E., Kim, K., Oh, B.., \& Hong, C., (2009): Nutritional risk and cognitive impairment in the elderly. Archives of Gerontology and Geriatrics, 48(1), 95-99. doi: 10.1016/j.archger.2007.11.001

18. Morley, J., Thomas, D., \& ebrary, I., (2007): Geriatric nutrition. Boca Raton: Taylor \&amp; Francis/CRC.

19. Morris, M., Le, V., \& Maniam, J., (2016): The impact of poor diet and early life stress on memory status. Current Opinion in Behavioral Sciences, $\quad 9$, 144-151. doi: 10.1016/j.cobeha.2016.04.002

20. Oketcha, J., Patersona, M., Maunderb, E., \& Rollinsc N., (2011): Too little, too late: omparison of nutritional status and quality of life of nutrition care and support recipient and non-recipients among HIV-positive adults in KwaZulu-Natal, South Africa. Health Policy, 99, 267-276.

21. Rakıcıoğlu, N., Aksoy, B., Tamer, F., Yıldız, E., Samur, G., Pekcan, G., \& Besler, H., (2016): Nutritional status and eating habits of the institutionalised elderly in Turkey: a follow-up study. Journal of Human Nutrition and Dietetics, 29(2), 185-195. doi: 10.1111/jhn. 12320

22. Topală, I., (2014): Attitudes towards Academic Learning and Learning Satisfaction in Adult Students. Procedia - Social and Behavioral Sciences, 142, 227-234. doi: http://dx.doi.org/10.1016/j.sbspro.2014.07.583

23. Watson, R., \& Ebrary, I., (2009): Handbook of nutrition in the aged (4th ed.). Boca Raton: CRC Press.

24. WHO. (2015a): Ageing and life course Retrieved 5 October 2017, from www.who.int/ageing/en/index.html

25. WHO. (2015b). Egypt: Statistics Retrieved 5 October, 2017, from http://www.who.int/countries/egy/en/

26. Wunderlich, S., McKinnon, C., Piemonte, J., \& Ahmad, Z., (2009): Measuring the Impact of Nutrition Education and Physical Activity on Older Adults Participating in Government Sponsored Programs. Journal of Nutrition For the Elderly, 28(3), 255-271. doi: 10.1080/01639360903140189

27. Yang, S., Hsu, W., \& Chen, H., (2016): Age and gender's interactive effects on learning satisfaction among senior university students. Educational Gerontology, 42(12), 835-844. doi: 10.1080/03601277.2016.1231514

28. Zapatera, B., Prados, A., Gómez-Martínez, S., \& Marcos, A., (2015): Immunonutrition: methodology and applications. Nutr Hosp, 31(3), 145-154. 